\title{
Flexible polyurethane foams based on $100 \%$ renewably sourced polyols
}

\author{
L. Ugarte ${ }^{a}$, A. Saralegi ${ }^{b}$, R. Fernández ${ }^{a}$, L. Martín ${ }^{a}$, M.A. Corcuera ${ }^{a}$, A. Eceiza ${ }^{a}, *$ \\ a "Materials + Technologies" Group, Department of Chemical and Environmental Engineering, Polytechnic School, University of the Basque Country \\ (UPV/EHU), Pza Europa 1, 20018 Donostia-San Sebastian, Spain \\ ${ }^{\mathrm{b}}$ Laboratory of Separation and Reaction Engineering (LSRE), Associate Laboratory LSRE/LCM, Polytechnic Institute of Bragança, Campus Santa Apolónia Ap. \\ 1134, 5301-857 Bragança, Portugal
}

\section{A R T I C L E I N F O}

\section{Article history:}

Received 11 June 2014

Received in revised form 1 September 2014

Accepted 15 September 2014

Available online 5 October 2014

\section{Keywords:}

Microphase separation

AFM

Peak force quantitative nanomechanics

Vegetable oil based polyols

Flexible polyurethane foam

\begin{abstract}
A B S T R A C T
Since polyol is one of the major components in polyurethane foam synthesis, introducing renewably sourced polyols in the foam formulation leads to materials with high renewable carbon content. A series of flexible polyurethane foams with variations in polyol composition were synthesized with castor oil based Lupranol Balance ${ }^{\circledR} 50$ polyether polyol and corn based polytrimethylene ether glycol mixtures. Water was used as the unique and eco-friendly blowing agent. The effect of the relative amount of each polyol on the structure and properties was analyzed by optical microscopy, Fourier transform infrared spectroscopy, thermogravimetric analysis, tensile and compressive tests, dynamic mechanical analysis and atomic force microscopy. The average molecular weight and hydroxyl number of the polyol components showed to influence the foaming reaction and hence the structure and properties of the polyurethane foam. The newly developed peak force quantitative nano-mechanics technique was used to map the elastic modulus values of foam cell struts and it seemed to be adequate to assess the purity of the different phases.
\end{abstract}

(c) 2014 Elsevier B.V. All rights reserved.

\section{Introduction}

Flexible polyurethane foams have been widely used in many applications such as mattresses, seating and car industry and they are gaining great interest in areas such as biomedicine, intelligent materials and nanocomposites (Hodlur and Rabinal, 2014; Kang et al., 2013; Liu et al., 2013; Singhal et al., 2014). Nowadays, there is a growing concern about environmental issues in material synthesis. This reason together with crude price fluctuations have encouraged scientific community to develop materials, including polyurethanes, based on renewable resources which do not depend on petroleum based raw materials (Rashmi et al., 2013). Regarding renewable-based resources, vegetable oils have received special attention as raw materials for polyol synthesis (Ionescu et al., 2012; Narine et al., 2007; Palanisamy et al., 2011; Sharma et al., 2014). Helling and Rusell (2009) carried out a life cycle assessment analysis for vegetable oil based polyols and demonstrated that a reduction of $33-64 \%$ on fossil resources consumption as well as a lowering on greenhouse gas emissions could be achievable by using soy or castor oil.

\footnotetext{
* Corresponding author. Tel.: +34 943017185.

E-mail address: arantxa.eceiza@ehu.es (A. Eceiza).
}

Foam synthesis involves two main reactions: blowing and gelling. Blowing reaction arises from the reaction of an isocyanate group with water and yields urea and carbon dioxide, which expands the air bubbles entrapped inside the reactive mixture. Gelling reaction implies an isocyanate group and a hydroxyl group to form a urethane linkage. The microstructure is accepted to be composed by both physical and chemical crosslinks. Physical crosslinks arise when urea groups of sufficient size and concentration establish hydrogen bonding interactions with other urea groups and phase separate from soft segments into hard domains (Dounis and Wilkes, 1997). Chemical crosslinks are the result of the urethane reaction, whereby a covalent network is formed between polyurea oligomers and polyol soft segments through urethane bonds. The microstructure and morphology depend on several factors such as the competition between the two main reactions, mobility of urea groups, the level of crosslinks arised from the reaction between the diisocyanate and polyol and the specific interactions between polyol and polyurea segments (Heintz et al., 2005; Li et al., 2002).

Determining the mechanical properties on the micro-and nanoscale is a matter of interest in materials property analysis. Nanoindentation techniques are widely used to assess local mechanical properties. However, this method is time consuming and presents various uncertainties when determining the local 
elastic modulus (Miller et al., 2008; Varam et al., 2014). When working with soft materials such as polymers, the high deformations produced in the material and the importance of adhesive forces are important challenges when using nanoindentation analysis (Gupta et al., 2007; Kohn and Ebenstein, 2013; VanLandingham et al., 2011). Peak force quantitative nano-mechanics is a new technique that allows the mapping of mechanical properties by using a scanning probe microscope at a similar scanning speed to tapping mode. With difference to tapping mode atomic force microscopy, the controlled variable is the maximum force (peak force) applied to the surface and it is maintained constant during the scan. Force vs separation curves are obtained and information about adhesion force, elastic modulus, deformation and dissipation can be extracted (Adamcik et al., 2011). The reduced elastic modulus can be determined by using the Derjaguin-Muller-Toporov (DMT) model shown in Eq. (1) (Derjaguin et al., 1975).

$F_{\text {interaction }}=\frac{4}{3} E^{*} \sqrt{R\left(d-d_{0}\right)^{3}}$

where $F_{\text {interaction }}$ is the tip-sample force, $E^{*}$ is the reduced elastic modulus, $R$ is the tip radius and $d-d_{0}$ is sample deformation. (2).

The reduced modulus is related to the sample modulus by Eq.

$E^{*}=\left[\frac{1-v_{s}^{2}}{E_{s}}+\frac{1-v_{\text {tip }}^{2}}{E_{\text {tip }}}\right]^{-1}$

where $E^{*}$ is the reduced elastic modulus, $v_{s}$ and $v_{\text {tip }}$ are the Poisson's ratios of sample and tip respectively and $E_{s}$ and $E_{\text {tip }}$ are the elastic modulus of sample and tip respectively. Considering that $E_{\text {tip }}$ is much higher, sample Young's modulus $\left(E_{s}\right)$ can be calculated if $v_{s}$ is known (Pittenger et al., 2012).

The aim of this work was to synthesize flexible polyurethane foams using bio-derived polyols and to analyze the effect of variations in polyol composition over foam morphology and properties. Synthesis was carried out in a single step process and foams were cured in an open mold. Characterization was realized by optical microscopy, Fourier transform infrared spectroscopy (FTIR), thermogravimetric analysis (TGA), thermal conductivity measurements, tapping mode atomic force microscopy (TM-AFM), peak force quantitative nanomechanics atomic force microscopy (PFQNM-AFM), mechanical testing and dynamic mechanical analysis (DMA).

\section{Experimental}

\subsection{Raw materials and synthesis}

A series of flexible polyurethane foams with variations in polyol mixture composition were synthesized with castor oil based Lupranol Balance ${ }^{\circledR} 50$ polyether polyol, kindly supplied by BASF, and polytrimethylene ether glycol (PO3G) obtained from corn sucrose (Ugarte et al., 2014). Amine catalyst Tegoamin ${ }^{\circledR}$ B75 and tin catalyst $\operatorname{Kosmos}^{\circledR} 29$, together with surfactant Tegostab ${ }^{\circledR}$ B-4900 (all three from Evonik) and distilled water as blowing agent, were used in the B-side of the formulation. Toluene diisocyanate (TDI), generously supplied by Bayer, was used as diisocyanate in the A-side of the formulation. Hydroxyl number of Lupranol Balance ${ }^{\circledR} 50$ and PO3G were determined by titration according to ASTM D 4274-05. All reactants were used as received. Polyols main properties are summarized in Table 1.

Foams were synthesized at room temperature by reacting A-side with B-side in a two-step reaction. Polyol or polyols mixture, catalysts, water and surfactant were mixed at $2000 \mathrm{rpm}$ for $2 \mathrm{~min}$. Then, the fixed amount of TDI was incorporated and mixing continued for $10 \mathrm{~s}$ at the same speed. The mixture was then quickly poured into an
Table 1

Main properties of the polyols.

\begin{tabular}{lcc}
\hline Property & Lupranol Balance ${ }^{\circledR} 50$ & PO3G \\
\hline $\begin{array}{c}\text { OH number } \\
\left(\mathrm{mg} \mathrm{KOH} \mathrm{g}^{-1}\right)\end{array}$ & 49.7 & 79.4 \\
Functionality & 2.7 & 2 \\
$\begin{array}{l}\text { Number average } \\
\text { molecular weight }\end{array}$ & 3048 & 1413 \\
$\left(\mathrm{~g} \mathrm{~mol}^{-1}\right)$ & & \\
\hline
\end{tabular}

open mold to left the foam rise freely. Foams were cured at room temperature for at least $24 \mathrm{~h}$ before characterization. Isocyanate index was maintained constant (I.I.=120) in all foams. Maximum PO3G substitution was $20 \%$. With higher substitution values, foaming and gelling reactions were not well balanced with the fixed catalysts quantities and the obtained foams were not acceptable.

Foam designation and formulations are indicated in Table 2.

\subsection{Characterization techniques}

\subsubsection{Cell size and density}

Core density of samples was determined according to ASTM D3574-11, test A. Four measurements were made for each sample. Cell size of foams was analyzed by a Nikon Eclipse E 600 optical microscope. Twenty-five measurements of cell average diameter were made on each sample, using a $50 \times$ magnification lens.

\subsubsection{Fourier transform infrared spectroscopy}

Attenuated total reflectance Fourier transform infrared spectroscopy (ATR-FTIR) was used to characterize the functional groups of the synthesized polyurethane foams. Measurements were performed with a Nicolet Nexus FTIR spectrometer equipped with a MKII Golden Gate accessory, Specac, with diamond crystal as ATR element at a nominal incidence angle of $45^{\circ}$ with a ZnSe lens. Singlebeam spectra of the samples were obtained after averaging 64 scans in the range from 4000 to $800 \mathrm{~cm}^{-1}$ with a resolution of $4 \mathrm{~cm}^{-1}$. All spectra were obtained in the transmittance mode.

\subsubsection{Thermogravimetric analysis}

Analysis was performed on a TGA/SDTA 851 Metler Toledo equipment to evaluate thermal stability of polyurethane foams. Samples were heated from room temperature to $650^{\circ} \mathrm{C}$ at a heating rate of $10^{\circ} \mathrm{C} \mathrm{min}^{-1}$ under a nitrogen atmosphere. For comparison purposes, a foam with the same formulation to PF-100 but based on a petrochemical polyether polyol supplied by Repsol and named PF-PC, was also analyzed. It had an equivalent molecular weight of $1167 \mathrm{~g} \mathrm{eq}^{-1}$ and a hydroxyl number of $48 \mathrm{mg} \mathrm{KOH} \mathrm{g}^{-1}$. The formulation of PF-PC was adjusted in order to have similar cell size and density characteristics to PF-100 foam.

\subsubsection{Thermal conductivity}

Thermal conductivity measurements were carried out in a PVT 100 Haake equipment with a 556-1082 sensor model at $35^{\circ} \mathrm{C}$. Cylindrical-shaped foam samples with a diameter of $9 \mathrm{~mm}$ were

Table 2

Designation and formulation of synthesized polyurethane foams (PF). All formulations are based on 100 parts by weight of polyol (php).

\begin{tabular}{|c|c|c|c|c|c|}
\hline Component & PF100 & PF95 & PF90 & PF85 & PF80 \\
\hline Lupranol Balance ${ }^{\circledR} 50$ & 100 & 95 & 90 & 85 & 80 \\
\hline PO3G & - & 5 & 10 & 15 & 20 \\
\hline Water & 3.5 & 3.5 & 3.5 & 3.5 & 3.5 \\
\hline Tegoamin ${ }^{\circledR}$ B75 & 0.3 & 0.3 & 0.3 & 0.3 & 0.3 \\
\hline $\operatorname{Kosmos}^{\circledR} 29$ & 0.4 & 0.4 & 0.4 & 0.4 & 0.4 \\
\hline Tegostab ${ }^{\circledR}$ B-4900 & 1.1 & 1.1 & 1.1 & 1.1 & 1.1 \\
\hline TDI $(g)$ & 49.3 & 49.6 & 50.0 & 50.3 & 50.6 \\
\hline
\end{tabular}


prepared and sensor voltage was set at $2.5 \mathrm{~V}$. As data deviation was very low, two measurements were made for each sample.

\subsubsection{Atomic force microscopy}

Microstructure of cell struts was analyzed by TM-AFM. For specimen preparation, small pieces of foam were put in silicone rubber molds and they were filled with a low-viscosity epoxy mixture. The air entrapped inside foams was removed by applying low vacuum before curing the epoxy at $60^{\circ} \mathrm{C}$ for $24 \mathrm{~h}$. Specimens were cut with a Leica EM FC6 cryo-ultramicrotome equipped with a diamond knife and operated at $-120^{\circ} \mathrm{C}$. Images were obtained in tapping mode at room temperature with a Nanoscope IIIa scanning probe microscope (Multimode ${ }^{\mathrm{TM}}$ Digital Instruments), using an integrated force generated by cantilever/silicon probes, applying a resonance frequency of ca $180 \mathrm{kHz}$. The cantilevers were $125 \mathrm{Nm}$ long, with a tip radius of 5-10 $\mathrm{nm}$. Morphological and quantitative nanomechanical properties of foam cell struts were also analyzed by PFQNM-AFM using the epoxy embed foam samples. Since peak force tapping mode controls accurately the force applied, the deformation of the sample is small and located at the nano-scale. Thus, the possible reinforcement effect caused by the epoxy over the cell walls could be neglected. Measurements were carried out using a Bruker Dimension Icon AFM operated under peak force mode. High resolution mapping of elastic modulus was performed under room conditions with an integrated TAP 150A tip having a resonance frequency of $142-162 \mathrm{kHz}$, spring constant of ca. $3.6 \mathrm{Nm}^{-1}$ and estimated tip radius of $40 \mathrm{~nm}$. For comparison purposes, a foam based on PF100 formulation but with 6.5 php of water (designated as PF100H) was synthesized and epoxy embed, to observe differences in microstructure and nanomechanical properties when increasing urea percentage in the foam.

\subsubsection{Mechanical properties}

Tensile properties of polyurethane foams were analyzed according to ASTM D-3574-11, test E. A MTS equipment with a load cell of $250 \mathrm{~N}$ and pneumatic grips was used to measure the modulus of elasticity, ultimate tensile strength and percentage elongation at break. Tests were performed at a crosshead rate of $500 \mathrm{~mm} \mathrm{~min}^{-1}$. Tensile properties were averaged for at least three specimens.

Measurements of compression properties were carried out according to ASTM D-3574-11, test C in a MTS equipment with a load cell of $10 \mathrm{kN}$ and compression plates. Tests were performed at a crosshead rate of $50 \mathrm{~mm} \mathrm{~min}^{-1}$ and final force was determined after $60 \mathrm{~s}$. Three specimens per sample were at least analyzed.

All tensile and compressive properties were measured in the foam rise direction.

\subsubsection{Dynamic mechanical analysis}

DMA was performed in tensile mode with an Eplexor $100 \mathrm{~N}$ analyzer, Gabo equipment. Measurements were carried out at a scanning rate of $2{ }^{\circ} \mathrm{Cmin}^{-1}$ from -100 to $200^{\circ} \mathrm{C}$, using an initial strain of $2 \%$. The operating frequency was $1 \mathrm{~Hz}$. Approximate dimensions of foams were $20 \mathrm{~mm} \times 5.5 \mathrm{~mm} \times 3.5 \mathrm{~mm}$
Table 3

Density and cell size of synthesized foams.

\begin{tabular}{lll}
\hline Sample & Density $\left(\mathrm{kg} \mathrm{m}^{-3}\right)$ & Cell size $(\mu \mathrm{m})$ \\
\hline PF100 & $42.00 \pm 0.97$ & $263.29 \pm 74.21$ \\
PF95 & $40.65 \pm 0.97$ & $252.77 \pm 114.32$ \\
PF90 & $38.55 \pm 0.54$ & $287.54 \pm 150.24$ \\
PF85 & $39.20 \pm 0.65$ & $322.89 \pm 143.28$ \\
PF80 & $42.35 \pm 0.94$ & $275.39 \pm 103.47$ \\
\hline
\end{tabular}

(length $\times$ width $\times$ thickness). DMA measurements were also performed in the foam rise direction.

\section{Results and discussion}

\subsection{Density and cell size}

Density measurement results are shown in Table 3. Cellular structure and cell size of the foams were observed by optical microscopy (Fig. 1) and cell size values are also resumed in Table 3. It was observed that density decreased when increasing PO3G content until a $10 \%$ substitution, and then increased. The same tendency was observed by Tu et al. (2008) when substituting a petrochemical polyol with epoxidized soybean oil with higher hydroxyl number. Lim et al. (2008) analyzed the effect of polyol hydroxyl number in polyurethane foam formulations. They also observed that when increasing hydroxyl number while maintaining isocyanate index constant, the density reached a minimum and then increased. It was concluded that the decrease of the molecular weight when increasing hydroxyl number caused a better mobility of the mixture and the blowing efficiency increased. Upon the minimum value, the increase of viscosity due to the intensive formation of allophanate and biuret crosslinks is believed to hinder foaming reactions. Moreover, the increased reactivity of highest PO3G substitution polyol mixtures may have fastened the gelling reaction and the cell structure became strong enough before it was blown (Kang et al., 2012) keeping the cell size small.

PF90 had the lowest density and the highest cell anisotropy as well as one of the highest cell sizes. Cell size results showed a direct relationship with foam density. Foams with the highest density had the smallest cell sizes and lowest cell anisotropy. PF100 and PF80 showed very similar structures.

\subsection{FTIR}

ATR-FTIR results of polyurethane foams ranging from $100 \%$ to $80 \%$ Lupranol Balance ${ }^{\circledR} 50$ polyol showed transmittance bands corresponding to both main reactions taking place in polyurethane foam chemistry: urethane and urea bonds. As shown in Fig. 2, all spectra were quite similar but slight differences due to polyol composition were observed.

Transmittances at wavenumbers $1223 \mathrm{~cm}^{-1}$ and $1730 \mathrm{~cm}^{-1}$ were assigned to the ester asymmetric absorbance and the ester carbonyl absorbance (Singhal et al., 2014), respectively. It was
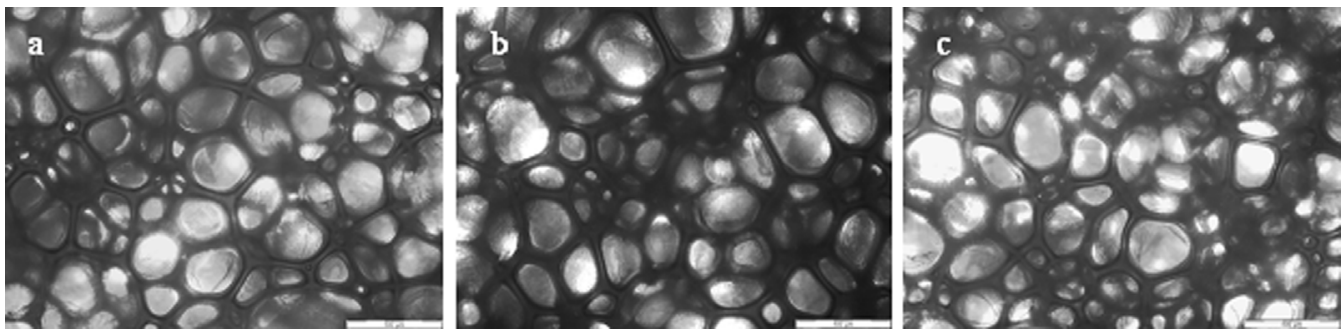

Fig. 1. Optical micrographs of (a) PF100, (b) PF90 and (c) PF80 polyurethane foams (scale bar: $200 \mu \mathrm{m}$ ). 


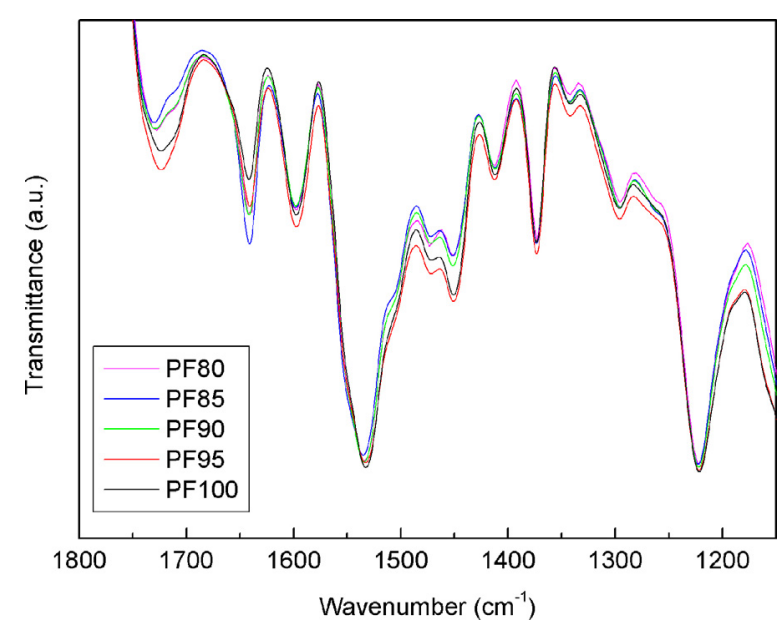

Fig. 2. FTIR spectra of the synthesized foams on the range from $1800 \mathrm{~cm}^{-1}$ to $1100 \mathrm{~cm}^{-1}$. (For interpretation of reference to color in this figure legend, the reader is referred to the web version of this article.)

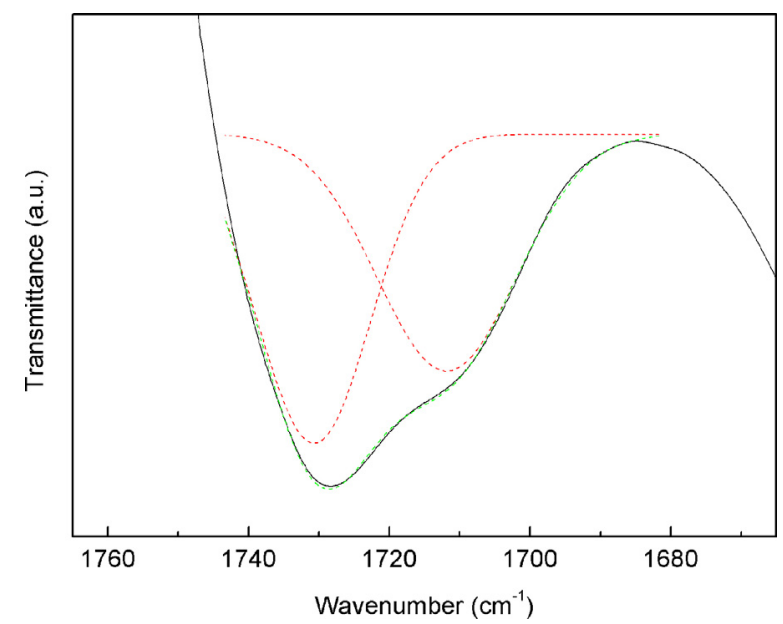

Fig. 3. Peak deconvolution for PF80 sample. (For interpretation of reference to color in this figure legend, the reader is referred to the web version of this article.)

observed that as the Lupranol Balance ${ }^{\circledR} 50$ content in the foam formulation decreased, ester carbonyl absorbance peak intensity diminished due to the incorporation of ether groups in the formulation instead of ester groups.

In the amide I region, the bands corresponding to free $\mathrm{C}=\mathrm{O}$ stretching of urea (around $1715 \mathrm{~cm}^{-1}$ ) and urethane (around $1730 \mathrm{~cm}^{-1}$ ) were observed (Elwell et al., 1996). The deconvolution of the observed peak allowed calculating the relative areas corresponding to each type of stretching. An example of the deconvolution is shown in Fig. 3.

The area and the wavenumber $(\mathrm{WN})$ corresponding to each peak are summarized in Table 4.

As PO3G content increased, shifts to lower wavenumbers were observed for both free urea and free urethane stretching vibration and the total area also diminished. On the same fashion,

Table 4

Analysis of free urethane and free urea areas for PF100, PF90 and PF80 samples.

\begin{tabular}{lrlllll}
\hline \multirow{2}{*}{ Sample } & \multicolumn{2}{l}{ Free urethane } & & \multicolumn{2}{l}{ Free urea } & \multirow{2}{*}{$R$ urea/urethane } \\
\cline { 2 - 3 } & Area & WN & & Area & WN & \\
\hline PF100 & 77.2 & 1734 & & 267.8 & 1716 & 3.5 \\
PF90 & 89.8 & 1733 & & 145.0 & 1715 & 1.6 \\
PF80 & 108.1 & 1731 & & 101.9 & 1712 & 0.9 \\
\hline
\end{tabular}

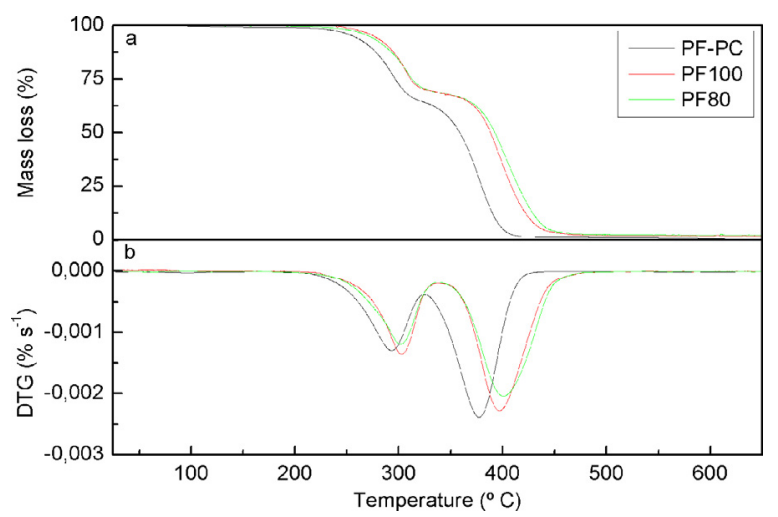

Fig. 4. (a) TGA thermograms of PF-PC, PF100 and PF80 foams and (b) DTG curves of PF-PC, PF100 and PF80 foams. (For interpretation of reference to color in this figure legend, the reader is referred to the web version of this article.)

urea/urethane ratio value diminished as PO3G content increased. Results suggest that as PO3G is incorporated in the formulation, ureas may be able to form ordered domains as less free urea groups were observed by ATR-FTIR analysis.

The transmittance band at $1640 \mathrm{~cm}^{-1}$ corresponds to bidentate (hydrogen bonded) urea and could be used as an identification of ordered hard domains (Heintz et al., 2005). As a general tendency, it was observed that foams with the highest quantity of PO3G in the formulation showed the most intense peaks. The results agree with the deconvolution analysis, indicating the formation of more ordered urea domains as the short glycol is incorporated in the formulation.

\subsection{Thermal properties}

Thermal degradation properties of polyurethane foams are essential regarding a safe use. In this way, the thermal degradation behavior of bio-based polyurethane foams was compared with a petrochemical polyol based foam. Thermograms of polyurethane foams under nitrogen atmosphere are shown in Fig. 4. Petrochemical polyol based foam maintained stable until $200^{\circ} \mathrm{C}$, while bio-based polyurethane foams started degradation around $220^{\circ} \mathrm{C}$. Results showed that degradation occurred in two steps. The first step was assigned to degradation of urea and urethane linkages (Ravey and Pearce, 1997). According to first derivative thermogravimetric (DTG) curve, the maximum urea and urethane degradation rate for the petrochemical polyol based foam and biobased foams were detected at $290^{\circ} \mathrm{C}$ and $300^{\circ} \mathrm{C}$ respectively. The second step corresponds to polyol degradation (Allan et al., 2013). Analyzing the maximum degradation rate temperature, bio-based polyols conferred enhanced thermal stability $\left(400^{\circ} \mathrm{C}\right)$ comparing with petrochemical polyether polyol $\left(377^{\circ} \mathrm{C}\right)$. Char formation was negligible in all cases, with a maximum of $2.3 \%$ for PF100 foam.

Thermal conductivity values of foams were very similar with an average of $0.069 \mathrm{~W} \mathrm{~m}^{-1} \mathrm{~K}^{-1}$, indicating that they all have similar open-closed cell proportions. Values were quite high comparing with other data reported in literature for foams obtained from both vegetable oil based polyols and petrochemical polyols (Badri, 2012; Jeong et al., 2009). This could be due to the foam disposition during the analysis, which could be slightly compressed by the temperature probe.

\subsection{Foam strut morphology and elastic modulus}

TM-AFM was used to obtain phase images of PF100 and PF80 polyurethane foams (Fig. 5). High dissipating soft phases give dark contrast while rigid phases are identified as bright areas. More rigid 

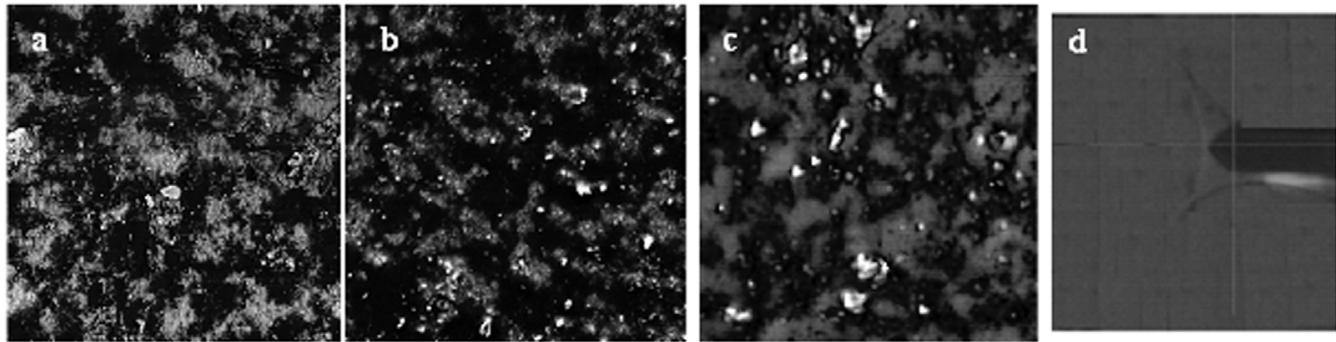

Fig. 5. AFM $5 \mu \mathrm{m} \times 5 \mu \mathrm{m}$ tapping mode phase images of (a) PF100, (b) PF80, and (c) PF100H and (d) positioning of AFM tip on cell strut.

(Yilgor and Yilgor, 2007), urea rich regions may appear brighter than polyol soft regions (Aneja and Wilkes, 2002). On the analyzed figures, microphase segregation of different phases was observed (Lan and Haugstad, 2011) with bright regions dispersed in a dark continuous phase. According to relative dissipation energies, it was concluded that bright regions correspond to urea rich domains dispersed in polyol rich domains. In PF80 sample, soft polyol domains seemed to be purer since in PF100 sample more small bright crystals were observed dispersed in soft domains. Comparing PF100 and PF100H samples, it could be said that in PF100H, the urea hard domains create a more interconnected network across the continuous soft domain.

Topographic and elastic modulus mapping images obtained with PFQNM-AFM are shown in Fig. 6. Represented elastic modulus profiles were randomly selected from dark, low modulus areas. To obtain an average modulus value of such regions, six profiles
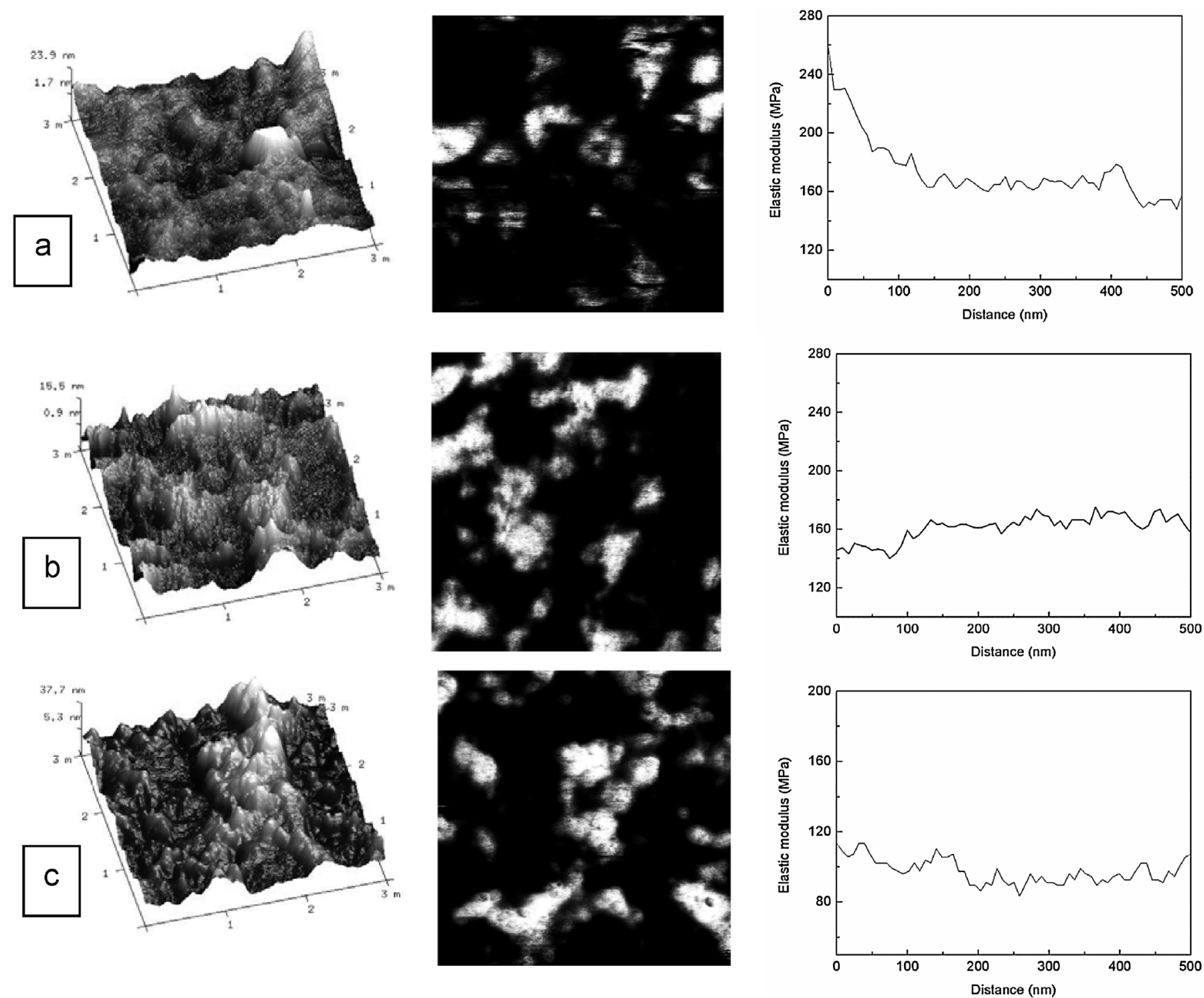

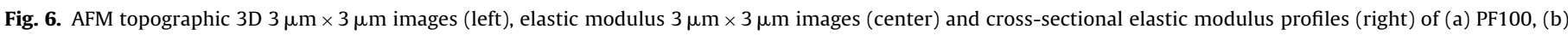
PF80 and (c) PF100H samples obtained from PFQNM-AFM. 
Table 5

Roughness and elastic modulus data of PF100, PF80 and PF100H samples.

\begin{tabular}{llll}
\hline Sample & \multicolumn{2}{l}{ Roughness $(\mathrm{nm})$} & Elastic modulus (MPa) \\
\cline { 2 - 3 } & $R_{a}{ }^{\mathrm{a}}$ & $R_{q}{ }^{\mathrm{b}}$ & \\
\hline PF100 & 4.25 & 5.92 & $191 \pm 44$ \\
PF80 & 3.18 & 4.07 & $159 \pm 10$ \\
PF100H & 7.58 & 9.54 & $106 \pm 12$ \\
\hline
\end{tabular}

a Arithmetic average roughness.

b Root mean square roughness.

were extracted and the average value was calculated on each sample. Results together with sample roughness are summarized in Table 5.

On elastic modulus mapping images, bright areas with high modulus were clearly distinguished from low modulus dark regions. Given that polyureas are more rigid that polyurethanes (Yilgor and Yilgor, 2007), it might be determined that bright areas correspond to urea rich domains. Taking this into account, the images are in accordance with TM-AFM phase images, where urea rich domains appear dispersed in a soft segment rich matrix. Modulus values were quite in accordance with previous works. For instance, Schön et al. (2011) used peak force quantitative nano-mechanics equipment to characterize the elastic modulus of segmented thermoplastic polyurethanes. Obtained modulus values were of the same order of magnitude although those of foams were higher. The increase of modulus on foams was attributed to the urea domains dispersed in the soft domains. The decrease in modulus from PF100 to PF80 could indicate a better phase separation as PO3G is introduced in the formulation. A purer soft phase involved a lower number of urea domains dispersed in the polyol rich phase and this may have lowered the average modulus of the soft phase in PF80 sample. This result was in accordance with FTIR analysis. PF100H sample showed the lowest modulus in dark phases, suggesting that the increased urea quantity on this foam favored their association and thus phase separation was enhanced. Roughness values increased both as PO3G was eliminated from polyol composition and more water was incorporated in the formulation.

\subsection{Mechanical properties}

Results concerning tensile strength, elastic modulus and ultimate elongation are shown in Fig. 7.

Tensile properties showed a very similar behavior to density and cell size. As a general tendency, it was observed that as foam density increased and cell size decreased, tensile behavior enhanced. PF90 showed the poorest tensile properties, the foam with highest cell size and one of the highest cell anisotropy. Compression force

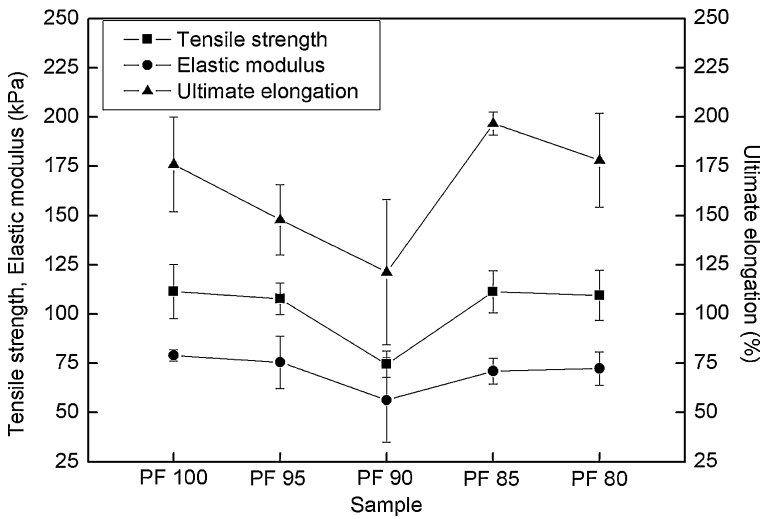

Fig. 7. Tensile strength ( $\boldsymbol{\square})$, elastic modulus ( $(\bullet)$ and ultimate elongation $(\boldsymbol{\Delta})$ of synthesized samples.

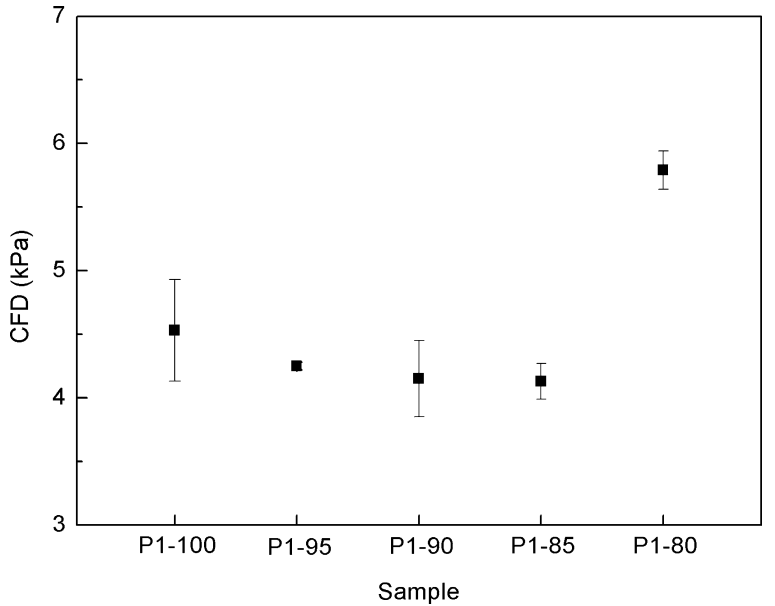

Fig. 8. CFD values of synthesized foams.

deflection (CFD) value results are shown in Fig. 8. According to Tu et al. (2008), compressive properties of foams seem to be influenced by both density and crosslinking density. On synthesized series, as PO3G has higher hydroxyl value than Lupranol Balance ${ }^{\circledR}$ 50 , the number of equivalent $\mathrm{OH}$ groups increased with the incorporation of PO3G to the formulation. Since isocyanate index was maintained constant in all samples, the quantity of NCO groups in the foam increased with the addition of PO3G. It seemed that until $10 \%$ of PO3G substitution, the effect of density decrease overlapped crosslinking effect and CFD values were not enhanced. However, in foams with high PO3G substitution, both density and crosslinking density increased and compressive properties increased, especially in PF80 sample.

\subsection{Dynamic mechanical properties}

The evolution of storage modulus and $\tan \delta$ values with temperature was analyzed by DMA (Fig. 9). Storage modulus showed two plateau regions, the one at low temperatures corresponding to glassy state and the one at high temperatures corresponding to rubbery state of the foam. Obtained values were quite similar, however, the porous nature of the foams made very difficult to measure the real area and hence to obtain reliable modulus values (Das et al., 2009). This drawback is avoided in $\tan \delta$ analysis since values are not influenced by the sample area. According to storage modulus evolution, samples showed a single $\tan \delta$ peak at around $-40^{\circ} \mathrm{C}$, corresponding to the beginning of molecular motions in the polyol

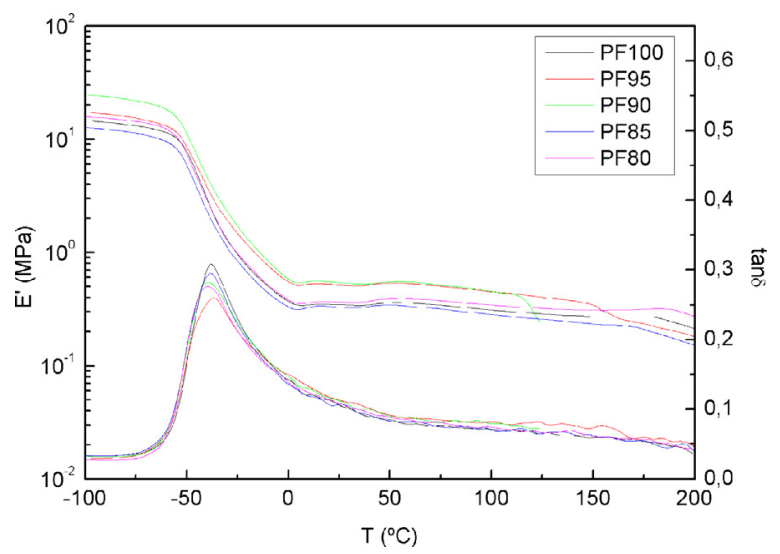

Fig. 9. Storage modulus $\left(E^{\prime}\right)$ and $\tan \delta$ as a function of temperature for synthesized foams. (For interpretation of reference to color in this figure legend, the reader is referred to the web version of this article.) 
chains. Results were similar to other works with bio-based polyols (Das et al., 2009; Sonnenschein and Wendt, 2013; Tu et al., 2009). As a general tendency, glass transition temperature values slightly shifted to lower temperatures as PO3G was incorporated to the polyol mixture.

\section{Conclusions}

Bio-based polyols showed to be good candidates for being used in flexible polyurethane foam synthesis. Foams with polyol mixtures ranging from $100 \%$ castor oil based Lupranol Balance ${ }^{\circledR}$ to $20 \%$ of PO3G substitution were successfully synthesized by a one shot method in an open mold. Foams with an open celled structure and acceptable densities were obtained. Results indicated that the incorporation of PO3G in the formulation favored hydrogen bonding between urea groups, suggesting that phase separation was enhanced. Bio-based foams showed improved thermal stability, with no significant mass loss until $220^{\circ} \mathrm{C}$. Morphological analysis of foam struts revealed the existence of a phase separated structure. Nanomechanical properties of different phases were measured by peak force quantitative nanomechanics AFM and results were satisfactorily used to asses phase separation in polyurethane foam strut. Observations suggested that phase separation was enhanced when incorporating PO3G in the polyol formulation. Polyol composition was believed to alter the reactivity and obtained three-dimensional structures, thus affecting mechanical properties of the foams.

\section{Acknowledgements}

Authors thank financial support from University of the Basque Country (PIFUPV047/2011), Basque Government (IT776-13 and SPE13UN091), Spanish Ministry of Economy and Competitiveness (MINECO) (IPT-2012-0728-420000) and European Union (PIRSES2012-318996). Technical support provided by SGIker (UPV/EHU, MINECO, GV/EJ, ESF) is gratefully acknowledged.

\section{References}

Adamcik, J., Berquand, A., Mezzenga, R., 2011. Single-step direct measurement of amyloid fibrils stiffness by peak force quantitative nanomechanical atomic force microscopy. Appl. Phys. Lett. 98, http://dx.doi.org/10.1063/1.3589369, 193701/1-193701/3.

Allan, D., Daly, J., Liggat, J.J., 2013. Thermal volatilization analysis of TDI-based flexible polyurethane foam. Polym. Degrad. Stab. 98, 535-541, http://dx.doi.org/ 10.1016/j.polymdegradstab.2012.12.002.

Aneja, A., Wilkes, G.L., 2002. On the issue of urea phase connectivity in formulations based on molded flexible polyurethane foams. J. Appl. Polym. Sci. 85, 2956-2967, http://dx.doi.org/10.1002/app.10863.

Badri, K.H., 2012. Biobased polyurethane from palm kernel oil-based polyol. Polyurethane, 447-470, http://dx.doi.org/10.5772/47966.

Das, S., Dave, M., Wilkes, G.L., 2009. Characterization of flexible polyurethane foams based on soybean-based polyols. J. Appl. Polym. Sci. 112, 299-308, http://dx.doi.org/10.1002/app.29402.

Derjaguin, B.V., Muller, V.M., Toporov, Y.P., 1975. Effect of contact deformations on adhesion of particles. J. Colloid Interface Sci. 53, 314-326, http://dx.doi.org/ 10.1016/0021-9797(75)90018-1.

Dounis, D.V., Wilkes, G.L., 1997. Structure-property relationships of flexible polyurethane foams. Polymer 11, 2819-2828, http://dx.doi.org/10.1016/S00323861(97)85620-0.

Elwell, M.J., Ryan, A.J., Grünbauer, H.J.M., Van Lieshout, H.C., 1996. Insitu studies of structure development during the reactive processing of model flexible polyurethane foam systems using FT-IR spectroscopy, synchrotron SAXS, and rheology. Macromolecules 29, 2960-2968, http://dx.doi. org/10.1021/MA9511208.

Gupta, S., Carrillo, F., Cheng, L., Pruitt, L., Puttlitz, C., 2007. Adhesive forces significantly affect elastic modulus determination of soft polymeric materials in nanoindentation. Mater. Lett. 61, 448-451, http://dx.doi.org/ 10.1016/j.matlet.2006.04.078.

Heintz, A.M., Duffy, D.J., Nelson, C.M., Hua, Y., Hsu, S.L., 2005. A spectroscopic analysis of the phase evolution in polyurethane foams. Macromolecules 38, 9192-9199, http://dx.doi.org/10.1021/ma051599w.

Helling, R.K., Rusell, D.A., 2009. Use of life cycle assessment to characterize the environmental impacts of polyol products options. Green Chem. 11, 380-389, http://dx.doi.org/10.1039/b815833a.
Hodlur, R.M., Rabinal, M.K., 2014. Self assembled graphene layers on polyurethane foams as highly pressure sensitive conducting composite. Compos. Sci. Technol. 90, 160-165, http://dx.doi.org/10.1016/j.compscitech.2013.11.005.

Ionescu, M., Wan, X., Bilić, N., Petrović, Z.S., 2012. Polyols and rigid polyurethane foams from cashew nut shell liquid. J. Polym. Environ. 20, 647-658, http://dx.doi.org/10.1007/s10924-012-0467-9.

Jeong, Y.-S., Choi, H.-J., Kim, K.-W., Choi, G.-S., Kang, J.-S., Yang, K.-S., 2009. A study on the thermal conductivity of resilient materials. Thermochim. Acta 490, 47-50, http://dx.doi.org/10.1016/j.tca.2009.02.015.

Kang, S.M., Lee, S.J., Kim, B.K., 2012. Shape memory polyurethane foams. Express Polym. Lett. 6, 63-69, http://dx.doi.org/10.3144/expresspolymlett.2012.7.

Kang, S.M., Kwon, S.H., Park, J.H., Kim, B.K., 2013. Carbon nanotube reinforced shape memory polyurethane foam. Polym. Bull. 70, 885-893, http://dx.doi.org/ 10.1007/s00289-013-0905-4.

Kohn, J.C., Ebenstein, D.M., 2013. Eliminating adhesion errors in nanoindentation of compliant polymers and hydrogels. J. Mech. Behav. Biomed. 20, 316-326, http://dx.doi.org/10.1016/j.jmbbm.2013.02.002.

Lan, Q., Haugstad, G., 2011. Characterization of polymer morphology in polyurethane foams using atomic force microscopy. J. Appl. Polym. Sci. 121, 2644-2651, http://dx.doi.org/10.1002/app.34005.

Li, W., Ryan, A.J., Meier, I.K., 2002. Effect of chain extenders on the morphology development in flexible polyurethane foam. Macromolecules 35, 6306-6312 http://dx.doi.org/10.1021/ma0202311.

Lim, H., Kim, S.H., Kim, B.K., 2008. Effects of the hydroxyl value of polyol in rigid polyurethane foams. Polym. Adv. Technol. 19, 1729-1734, http://dx.doi. org/10.1002/pat.1188.

Liu, H., Liu, Z., Yang, M., He, Q., 2013. Superhydrophobic polyurethane foam modified by graphene oxide. J. Appl. Polym. Sci. 130, 3530-3536, http://dx.doi. org/10.1002/app.39406.

Miller, M., Bobko, C., Vandamme, M., Ulm, F.J., 2008. Surface roughness criteria for cement paste nanoindentation. Cem. Concr. Res. 38, 467-476, http://dx.doi.org/10.1016/j.cemconres.2007.11.014.

Narine, S.S., Kong, X., Bouzidi, L., Sporns, P., 2007. Physical properties of polyurethanes produced from polyols from seed oils: II. Foams. J. Am. Oil Chem. Soc. 84, 65-72, http://dx.doi.org/10.1007/s11746-006-1008-2.

Palanisamy, A., Rao, B.S., Mehazabeen, S., 2011. Diethanolamides of castor oil as polyols for the development of water-blown polyurethane foam. J. Polym. Environ. 19, 698-705, http://dx.doi.org/10.1007/s10924-011-0316-2.

Pittenger, B., Erina, N., Su, C., 2012. Bruker Application Note AN128, Rev. B0.

Rashmi, B.J., Rusu, D., Prashantha, K., Lacrampe, M.F., Krawczak, P., 2013. Development of water-blown bio-based thermoplastic polyurethane foams using bio-derived chain extender. J. Appl. Polym. Sci. 128, 292-303, http://dx.doi.org/10.1002/app.38183.

Ravey, M., Pearce, E.M., 1997. Flexible polyurethane foam: I. Thermal decomposition of a polyether-based, water-blown commercial type of flexible polyurethane foam. J. Appl. Polym. Sci. 63, 47-74, DOI:10.1002/(SICI)10974628(19970103)63:1<47::AID-APP7>3.0.CO;2-S.

Schön, P., Bagdi, K., Molnár, K., Markus, P., Pukánszky, B., Vansco, G.J., 2011. Quantitative mapping of elastic moduli at the nanoscale in phase separated polyurethanes by AFM. Eur. Polym. J. 47 (4), 692-698, http://dx.doi.org/ 10.1016/j.eurpolymj.2010.09.029.

Sharma, C., Kumar, S., Unni, A.R., Aswal, V.K., Rath, S.K., Harikrishnan, G., 2014 Foam stability and polymer phase morphology of flexible polyurethane foams synthesized from castor oil. J. Appl. Polym. Sci. 131 (17), 406681-406688, http://dx.doi.org/10.1002/app.40668.

Singhal, P., Small, W., Cosgriff-Hernandez, E., Maitland, D.J., Wilson, T.S., 2014. Low density biodegradable shape memory polyurethane foams for embolic biomedical applications. Acta Biomater. 10, 67-76, http://dx.doi.org/ 10.1016/j.actbio.2013.09.027.

Sonnenschein, M.F., Wendt, B.L., 2013. Design and formulation of soybean oil derived flexible polyurethane foams and their underlying polymer structure/property relationships. Polymer 54, 2511-2520, http://dx.doi.org/ 10.1016/j.polymer.2013.03.020.

Tu, Y.C., Suppes, G.J., Hsieh, F.H., 2008. Water-blown rigid and flexible polyurethane foams containing epoxidized soybean oil triglycerides. J. Appl. Polym. Sci. 109, 537-544, http://dx.doi.org/10.1002/app.28153.

Tu, Y.C. Suppes, G.J., Hsieh, F.H., 2009. Thermal and mechanical behavior of flexible polyurethane-molded plastic films and water-blown foams with epoxidized soybean oil. J. Appl. Polym. Sci. 111, 1311-1317, http://dx.doi. org/10.1002/app.29178.

Ugarte, L., Fernández-d'Arlas, B., Valea, A., Gonzalez, M.L., Corcuera, M.A., Eceiza, A., 2014. Morphology-properties relationship in high renewable content polyurethanes. Polym. Eng. Sci. 54, 2282-2291, http://dx.doi.org/10.1002/ pen.23777.

VanLandingham, M.R., Villarubia, J.S., Guthrie, W.F., Meyers, G.F., 2011. Nanoindentation of polymers: an overview. Macromol. Symp. 167, 15-43, DOI:10.1002/1521-3900(200103)167:1<15::AID-MASY15>3.0.CO; T.

Varam, S., Rajulapati, K.V., Bhanu Sankara Rao, K., 2014. Strain rate sensitivity studies on bulk nanocrystalline aluminium by nanoindentation. J. Alloys Compd. 585 795-799, http://dx.doi.org/10.1016/j.jallcom.2013.09.116.

Yilgor, I., Yilgor, E., 2007. Structure-morphology-property behavior of segmented thermoplastic polyurethanes and polyureas prepared without chain extenders. Polym. Rev. 47 (4), 487-510, http://dx.doi.org/10.1080/15583720701638260. 